\title{
Technology assessment of thermal treatment technologies using ORWARE
}

\author{
G. Assefa *, O. Eriksson, B. Frostell \\ Division of Industrial Ecology, Royal Institute of Technology, Stockholm S-10044, Sweden
}

Received 28 June 2003; received in revised form 3 April 2004; accepted 29 April 2004

Available online 3 July 2004

\begin{abstract}
A technology assessment of thermal treatment technologies for wastes was performed in the form of scenarios of chains of technologies. The Swedish assessment tool, ORWARE, was used for the assessment. The scenarios of chains of thermal technologies assessed were gasification with catalytic combustion, gasification with flame combustion, incineration and landfilling. The landfilling scenario was used as a reference for comparison. The technologies were assessed from ecological and economic points of view.

The results are presented in terms of global warming potential, acidification potential, eutrophication potential, consumption of primary energy carriers and welfare costs. From the simulations, gasification followed by catalytic combustion with energy recovery in a combined cycle appeared to be the most competitive technology from an ecological point of view. On the other hand, this alternative was more expensive than incineration. A sensitivity analysis was done regarding electricity prices to show which technology wins at what value of the unit price of electricity $(\mathrm{SEK} / \mathrm{kW} \mathrm{h})$.

Within this study, it was possible to make a comparison both between a combined cycle and a Rankine cycle (a system pair) and at the same time between flame combustion and catalytic combustion (a technology pair). To use gasification just as a treatment technology is not more appealing than incineration, but the possibility of combining gasification with a combined cycle is attractive in terms of electricity production.

This research was done in connection with an empirical R\&D work on both gasification of waste and catalytic combustion of the gasified waste at the Division of Chemical Technology, Royal Institute of Technology (KTH), Sweden.
\end{abstract}

(C) 2004 Elsevier Ltd. All rights reserved.

Keywords: Technology assessment; Material flow analysis; Substance flow analysis; Life cycle assessment; Life cycle costing; Thermal technologies; ORWARE

\footnotetext{
${ }^{*}$ Corresponding author. Tel.: +46-8-790-9331; fax: +46-8-790-5034.
}

E-mail address: getachew@ket.kth.se (G. Assefa). 


\section{Introduction}

There are many tools for assessment of the different impacts of human activities. Technology assessment (TA) is just one of such an array of tools meant for comparing and then selecting technologies that bring about a minimum of negative impacts and a maximum of positive ones. The closure of the US Congressional Office of Technology Assessment (OTA) in 1995 with criticism of, among other things, its methodology [1-4] has not led to the end of the concept and discussions of TA. Rather, issues of revitalising TA in the US and elsewhere have continued ever since this decision of closure was taken [5-8].

TA has the potential to provide knowledge about the impacts of technology. This knowledge is beyond the traditional knowledge referred to as "technological knowledge, the knowledge of how to do or make things" by Edwin Layton as cited in Pitt [9]. According to C.I. Lewis cited in Pitt, "the utility of knowledge lies in the control it gives us, through appropriate action, over the quality of our future experience" [9].

It is rather interesting that TA has gained global attention through UNEP's work on Environmental Technology Assessment (EnTA) [10,11]. The issues addressed in conventional TA and even in the seemingly focused EnTA are so many that there is need for a number of tools specialising in different issues. Since TA is about technology choices, comparison of different technology alternatives is a logical part of the assessment. A quantitative analysis makes comparisons and addition of parameter values across chains of technologies easier instead of using such ambiguous and subjective terms as "significant impact" and "slight increase" [12]. Moreover, TA tools with a holistic approach, allowing assessment of technologies from a systems perspective, are of great importance.

Once the appropriate quantitative tools with a systems approach that focuses on different aspects of TA are available, different technologies can be assessed in a comparative way. Thermal technologies are one part of the contemporary web of technologies that require such holistic assessment. Thermal technologies play a vital role in energy production systems. From a TA perspective, there is a need to assess the performance of these technologies in terms of other different aspects in addition to their primary goal of producing a certain magnitude of energy.

In employing different thermal technologies for energy production, there has been a gain in interest in catalytic combustion as an environmentally better alternative to flame combustion (e.g. low $\mathrm{NO}_{x}$ emission). This better performance has, however, not yet been quantified and assessed from a systems perspective. It is also unclear as to whether there is a weak point somewhere along the chain of technologies from the ecological, economic or technical point of view. Specifically, the technology of catalytic combustion as a downstream unit of thermal gasification technology is still under development. All studies being done around this technology lack a holistic approach. Life cycle thinking should aid such studies in accounting for the role of upstream and downstream technology units that work with a specific technology on which developers traditionally focus their R\&D. Technology developers should be informed about the systems implications of their development work with the results of studies based on material/substance flow analysis, life cycle assessment and life cycle costing.

This paper is based on a technology assessment study performed at the Royal Institute of Technology, Sweden. The aim of this study was to assess the energy turnover as well as the 
potential ecological impacts and economic costs of thermal treatment technologies with the focus on catalytic combustion. In performing the study, a simultaneous interest was in developing and testing the ORWARE model in a new application area of technology assessment [13].

\section{Methodology}

In this technology assessment of thermal treatment technologies for wastes with focus on ecological and economic aspects, the ORWARE tool was used. Originally, the ORWARE model was developed for environmental systems analysis of waste management [14]. In recent research projects, the model has been further developed with a focus on energy related waste management issues [15]. As a new area of application, its potential as an aid to the environmental technology chain assessment (ETCA) tool has been illustrated by Assefa et al. [16].

The ORWARE tool [17] carries with it the concepts of systems analysis [18], material flow analysis (MFA) [19], substance flow analysis (SFA) [20], life cycle assessment (LCA) [21] and life cycle cost (LCC) [22].

The data and information used in this study was strongly dependent on findings from an umbrella project where gasification and catalytic combustion were studied from a technical point of view [23]. Emission and energy data from this project, together with literature data, were used as an input to ORWARE simulations in this study. The ecological performance (emissions and resource use in terms of primary energy consumption) and economic performance (both internal and external parts of LCC) of the catalytic combustion technology relative to other technologies constructed in the form of scenarios were simulated.

\section{Scenario descriptions}

In all scenarios, the time frame of the assessment was one year. In other words, an annual amount of waste was taken as input to the system. The functions of the system were (a) treatment of 32000 tonnes of industrial waste (containing household waste, paper waste, polyethene and wood residue) with the detailed composition shown in Table 1, (b) generation of electrical power and (c) generation of district heating by energy recovery from the waste treatment.

The amount of electricity and district heating is defined by the system itself as the maximum net amount generated in any of the simulated scenarios. The potential ecological and economic impacts were, however, not limited to one year, as emissions from a landfill normally are of long term character. Four different treatment scenarios were studied:

1. Thermal gasification with catalytic combustion

2. Thermal gasification with flame combustion

3. Incineration with energy recovery and

4. Landfilling with gas collection. 
Table 1

Composition of waste input

\begin{tabular}{ll}
\hline Parameter & $\mathrm{kg} / \mathrm{kg}$ waste \\
\hline VS (volatile solid) & 0.59 \\
$\mathrm{TS}$ (total solid) & 0.70 \\
$\mathrm{H}_{2} \mathrm{O}$ & 0.30 \\
$\mathrm{~S}-$ tot & $8.83 \times 10^{-4}$ \\
$\mathrm{Cl}-$ tot & $1.68 \times 10^{-3}$ \\
$\mathrm{~Pb}$ & $1.86 \times 10^{-6}$ \\
$\mathrm{Cd}$ & $2.86 \times 10^{-8}$ \\
$\mathrm{Hg}$ & $1.50 \times 10^{-8}$ \\
$\mathrm{Cu}$ & $5.37 \times 10^{-3}$ \\
$\mathrm{Cr}$ & $1.41 \times 10^{-5}$ \\
$\mathrm{Ni}$ & $1.97 \times 10^{-6}$ \\
$\mathrm{Zn}$ & $6.02 \times 10^{-5}$ \\
$\mathrm{Ash}$ & 0.11 \\
\hline
\end{tabular}

The first two scenarios were selected for a comparison of the new technology of catalytic combustion with conventional flame combustion. Both scenarios have the same type of gasification process. Scenario 3 was chosen to include a modern approach to direct thermal treatment, namely incineration. Since landfilling of combustible waste is forbidden by law in Sweden from 2002 and landfilling of organic waste from 2005, wastes being landfilled will have to be redirected to other treatment alternatives in many Swedish municipalities during the coming years. Scenario 4 was aimed at giving an illustration of the benefits of avoiding landfilling. The collection of wastes was not included as it would be the same for all scenarios. The transport distances used in the simulation, as indicated in the scenario description below, are based on waste management conditions in a middle sized municipality in southwestern Sweden.

Scenario 1 (Gasification with catalytic combustion $(G F-C C)$ ). The first scenario begins with the production of 24000 tonnes of pellets from the waste. By pelletising the waste, the water content is decreased, and the drying process consumes heat and electricity. Pelletising must be performed since the gasifier requires a homogenous fuel of high quality. The pellets are transported $5 \mathrm{~km}$ to a gasification site. The next step is the gasification process and then catalytic combustion of the product gas in a gas turbine. The process generates district heating and electrical power. Ash and slag are transported $30 \mathrm{~km}$ to a landfill site.

Scenario 2 (Gasification with flame combustion $(G F-F C)$ ). This scenario is the same as Scenario 1 except for the combustion technology used in the gas turbine. In this scenario, a conventional gas turbine with flame combustion is used.

Scenario 3 (Incineration $(I C)$ ). In this scenario, waste is transported $5 \mathrm{~km}$ from the point of collection to an incineration plant by truck. The waste is incinerated without pelletising, and both district heating and electrical power are generated. Ash and slag are transported $35 \mathrm{~km}$ to a landfill site. 


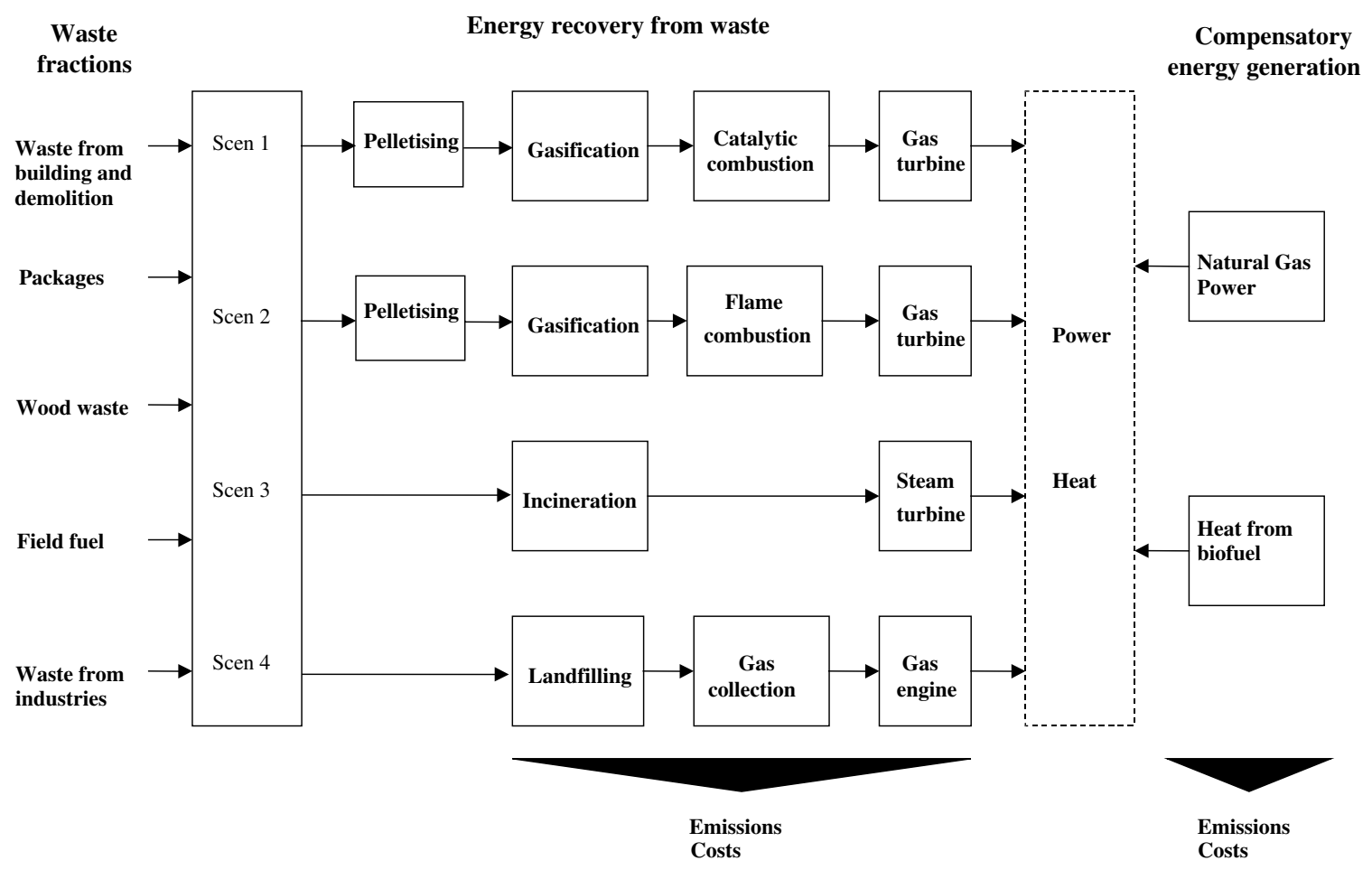

Fig. 1. Main technology chains in the different scenarios.

Scenario 4 (Landfilling $(L F)$ ). In the landfilling scenario, the unpelletised waste is transported 5 $\mathrm{km}$ to a waste landfill site from the point of collection. The landfill is equipped with a gas collection system, and electrical power is generated in a gas engine that combusts the collected landfill gas.

Fig. 1 illustrates the technology chains involved in each scenario.

\section{Assumptions and delimitations}

The fuel gas from the gasification is used in a combined cycle as it is considered to be a technically and economically feasible technology [24]. Further, the future technology chains in Scenarios 1 and 2 are assumed to perform properly. The compositions of the industrial wastes and the waste pellets were assumed to be the same except for the differences in water content.

Costs for gasification were based on pilot studies, while costs for catalytic combustion were assumed to be the same as those for flame combustion except an additional cost for the catalyst. The costs for the flame combustion and data on $\mathrm{NO}_{x}$ emissions are based on a pressurised gasification plant in the city of Värnamo, Sweden [25]. The assumption made was that there are no emission differences between the pressurised and the atmospheric gasification processes that precede the flame combustion. The atmospheric gasification technology is modelled in this study due to the prevailing condition in the area under consideration. 
It was also assumed that it is possible to use the existing landfilling model, originally developed for residues from incineration, for treating the residue from the thermal gasification process. A sensitivity analysis was performed for the residue as to whether the residue should be treated as slag or as ash.

There were also other assumptions, simplifications of reality and cost estimations made in this study and in the ORWARE tool $[13,26]$.

\section{Impact assessment}

The emissions from the studied system were classified and characterised using LCA methodology $[21,27]$ into the following ecological impact categories:

- Global warming potential

- Acidification potential

- Eutrophication potential

- Formation of photochemical oxidants

- Extraction of primary energy carriers

Other impact categories obtained in standardised LCA guidelines such as human health, biodiversity etc. were not included due to the lack of relevant data within the scope and budget of the project. This problem was also experienced in other studies that used ORWARE [28].

Since $\mathrm{NO}_{x}$ emissions are of crucial importance for the ecological performance of combustion technologies, they were assessed separately for the different scenarios.

Besides the ecological impact categories above, life cycle costs including internal costs and external cost were assessed. Internal costs covering the capital costs and operating costs were calculated in detail where revenues from purchases of district heating and electricity were included. In calculating the external cost, the emission data, including those accounting for the flow of heavy metals, were aggregated using a monetary valuation method [29]. No evaluation of resource use was performed.

\section{Results}

In all previous ORWARE applications of systems analysis of waste management, the total annual impact was of major interest. In this application of technology assessment, however, the ecological and economic impacts per unit of electricity delivered by each scenario was of interest. Electricity was selected as a unit of reference since the main reason for investing in a gasification plant would be to produce electricity. Such choice of main function is consistent with the tradition of conventional TA where the primary purpose of the technology at hand is at the core of the assessment work.

The energy flows in the different scenarios are summarised in Table 2. Based on local conditions and future developments, the compensatory systems for electricity and heat production considered for this study were natural gas and biomass, respectively. 
Table 2

Energy generation in the scenarios (all figures in GW h)

\begin{tabular}{lccrr}
\hline Type of energy & $\begin{array}{l}\text { Gasification with } \\
\text { catalytic combustion }\end{array}$ & $\begin{array}{l}\text { Gasification with } \\
\text { flame combustion }\end{array}$ & Incineration & Landfilling \\
\hline Electricity from pellets/waste (gross) & 56 & 56 & 30 & 15 \\
Internal electricity consumption & -11 & -11 & -2 & 0 \\
Electricity from pellets/waste (net) & 45 & 45 & 28 & 15 \\
Electricity from natural gas & 0 & 0 & +17 & +30 \\
Functional unit electricity & 45 & 45 & 45 & 45 \\
Heat from pellets/waste (gross) & 85 & 85 & 117 & 0 \\
Internal heat consumption & -6 & -6 & 0 & 0 \\
Heat from pellets/waste (net) & 79 & 79 & 117 & 0 \\
Heat from biomass (net) & +38 & +38 & 0 & 117 \\
Functional unit district heating & 117 & 117 & 117 & 117 \\
\hline
\end{tabular}

Table 3

Abbreviations/terms used in result presentation section

\begin{tabular}{lll}
\hline Abbreviations/terms & Represents & Location \\
\hline GF-CC & Gasification with catalytic combustion scenario & Figs. 2-10, Table 4 \\
GF-FC & Gasification with flame combustion scenario & Figs. 2-10, Table 4 \\
IC & Incineration scenario & Figs. 2-10, Table 4 \\
LF & Landfilling scenario & Figs. 2-10, Table 4 \\
GM & Gas engine & Table 4 \\
s.t. & Surveyable time & Figs. 2-4 \\
Core system & Gasification, flame and catalytic combustion, landfilling, & Discussion parts \\
& incineration, and transport & of Figs. 2-4 \\
\hline
\end{tabular}

In the following section, only parts of the result diagrams are presented. The emissions from landfilling that were taken into account were only those occurring during a defined surveyable time. This is assumed to be approximately 100 years. Emissions occurring during the remaining time (>100 years) were not considered. The abbreviations used on the $x$-axis of each diagram are presented in Table 3 for the sake of clarity.

\section{Global warming potential}

The highest contributions of greenhouse gases occur in the landfilling scenario and the lowest contribution is found for the gasification scenarios as shown in Fig. 2. The largest impact in the landfilling scenario is from the landfilling process where emissions of methane and laughing gas occur. A large contribution to the GWP is also from the emissions of combustion of natural gas (fossil $\mathrm{CO}_{2}$ ) for generation of compensatory electricity. For the incineration scenario, emissions of $\mathrm{CO}_{2}$ from natural gas use is dominating, but emission of laughing gas from the incineration plant also has some contribution. 


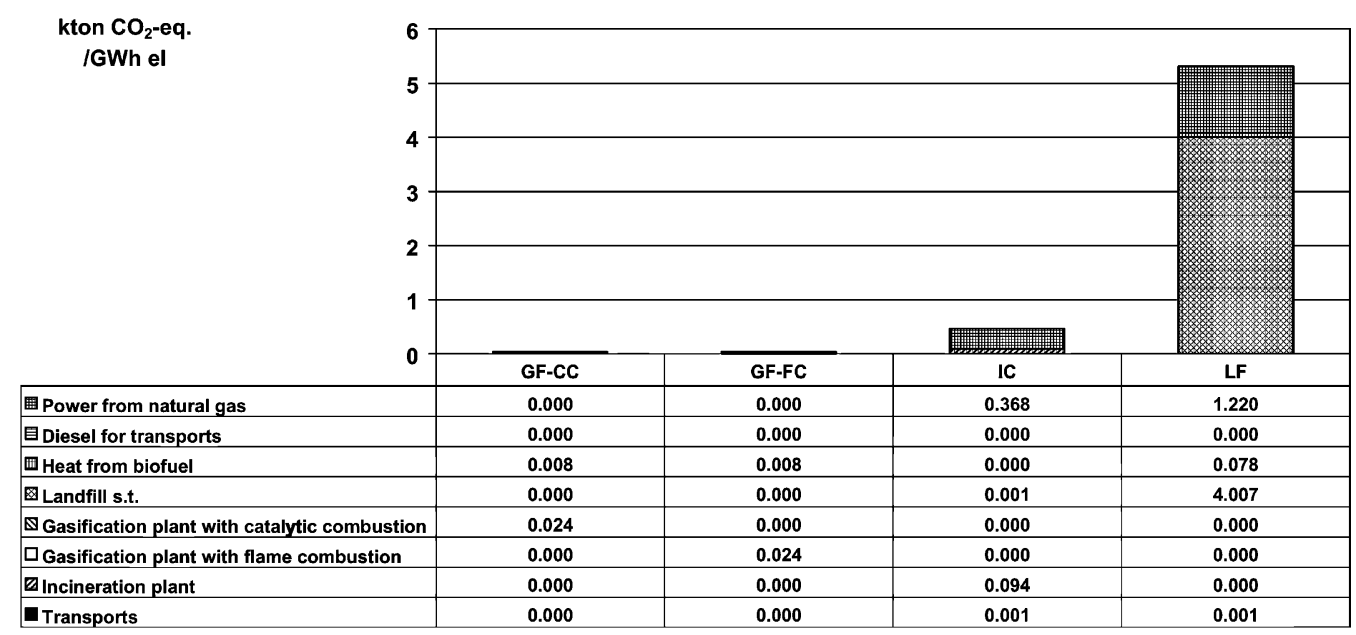

Fig. 2. Global warming potential.

\section{Acidification potential}

The landfilling scenario is the main contributor to acidification (Fig. 3). The lowest impact is found for the scenario with gasification followed by catalytic combustion. In all scenarios, the processes in the core system have a higher impact than those in the compensatory processes. Compensatory heat and power amount to about $1 / 3$ of the total impact for the landfilling scenario but much less for the other scenarios.

There are high emissions of nitrogen oxides from the landfill site and from the combustion of the collected landfill gas. Incineration of waste gives high emissions of ammonia compared to the

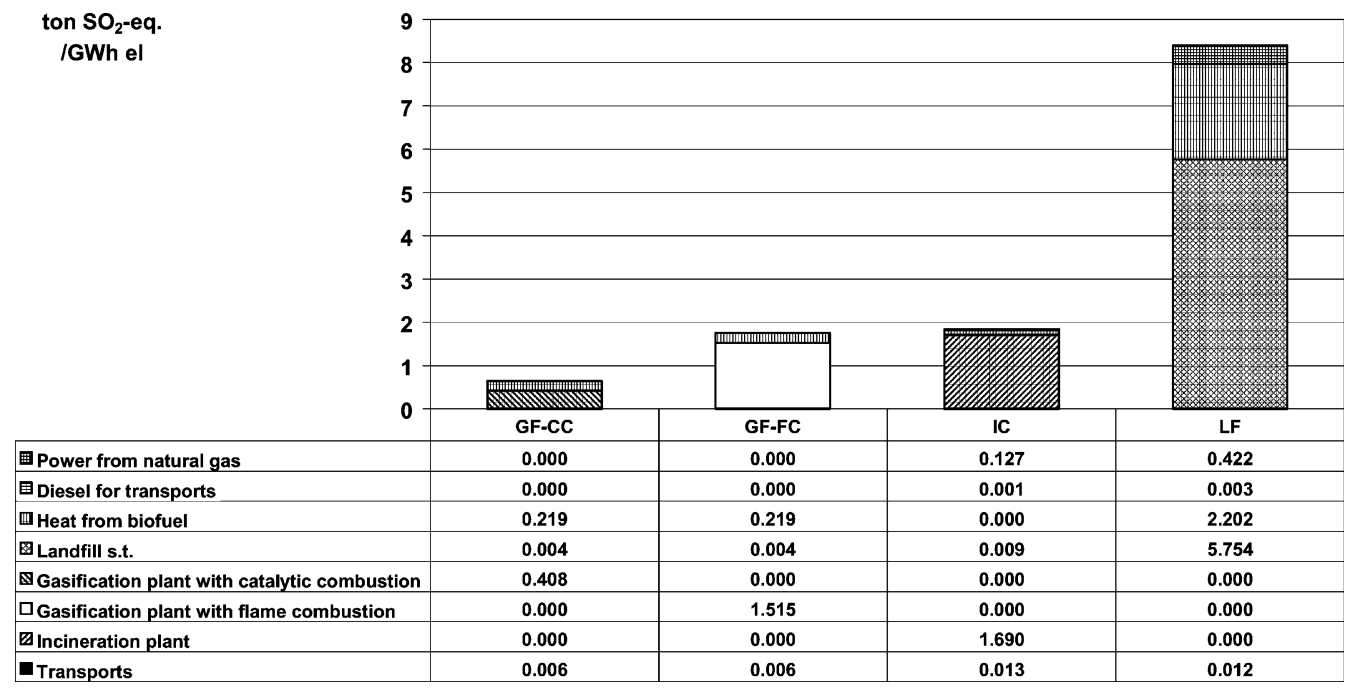

Fig. 3. Acidification potential. 
other treatment alternatives. The contribution to acidification from nitrogen dioxide is similar for the incineration scenario and the scenario for gasification and catalytic combustion, but the emissions of sulphur dioxide are higher for incineration. Chlorine emissions also give a contribution to acidification in the incineration scenario, while there are no such emissions from the other scenarios. There is a big difference between the two gasification scenarios. $\mathrm{The}^{\mathrm{NO}} \mathrm{O}_{x}$ emissions from the catalytic combustion are much lower than those from flame combustion.

\section{Eutrophication potential}

As shown in Fig. 4, the landfilling scenario has the highest impact, much above the other alternatives. The lowest impacts are found for the scenario with gasification followed by catalytic combustion and the incineration scenario, whereas the scenario with gasification followed by flame combustion has about 3 times higher impact. The core system dominates over the compensatory system in the contribution to eutrophication. The largest contribution from the landfilling process is from the nitrogen in the leachate and $\mathrm{NO}_{x}$ emissions from combustion of the landfill gas. Emissions of $\mathrm{NO}_{x}$ are much higher in flame combustion, which result in a relatively higher impact. The incineration scenario has more or less the same impact as the gasificationcatalytic combustion scenario. The small difference between these two is the result of higher $\mathrm{NO}_{x}$ emissions from the incineration plant and also some emissions of ammonia.

\section{Consumption of primary energy carriers}

As waste is landfilled, most of the energy in the waste is not recovered. This results in a consumption of biomass for compensatory heat generation and natural gas for compensatory power

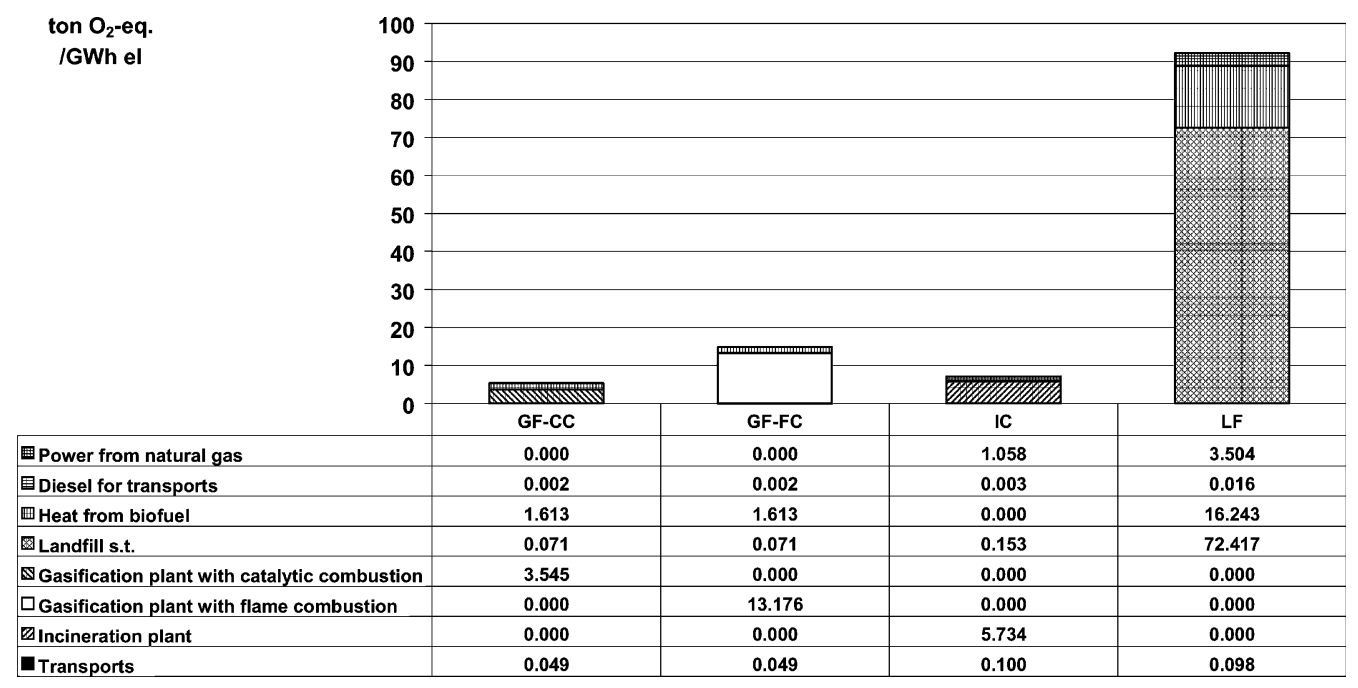

Fig. 4. Eutrophication potential. 


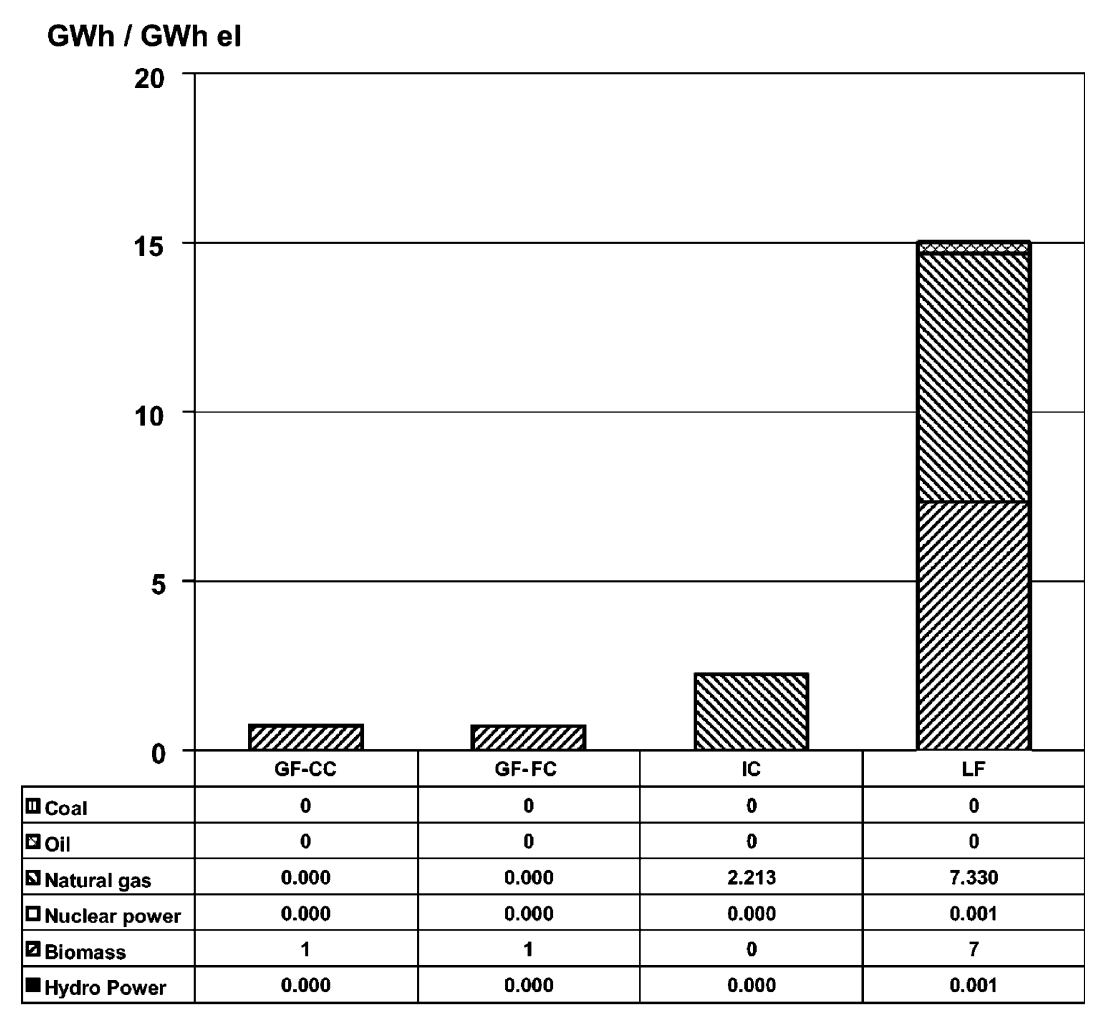

Fig. 5. Consumption of primary energy carriers.

generation. The incineration scenario determines the functional unit district heating (117 GW h), and there is only a consumption of natural gas for power generation (Table 2, Fig. 5). The gasification scenarios generate the maximum electricity $(45 \mathrm{GW} \mathrm{h})$ of all scenarios, but some heat for drying waste in the pelletising process, as well as compensatory heat, has to be provided from the combustion of biomass.

\section{Welfare costs}

Welfare costs are here defined as the sum of financial costs and environmental costs. In LCC terms, welfare cost is referred to as life cycle cost, whereas financial and environmental costs correspond to internal and external costs, respectively. The financial costs are the investment costs plus operating costs. The environmental costs are the price valuation of the emissions from each scenario [29] with a small reduction made for the environmental tax included in the Diesel price.

The highest cost is found for the landfilling scenario, which is explained by the combination of the overall high emissions and low energy recovery (Fig. 6). The incineration scenario has a total cost of about $1 / 6$ of the total cost for the landfilling scenario. The incineration scenario is the cheapest alternative. The environmental costs are highest for landfilling and least for incineration. 


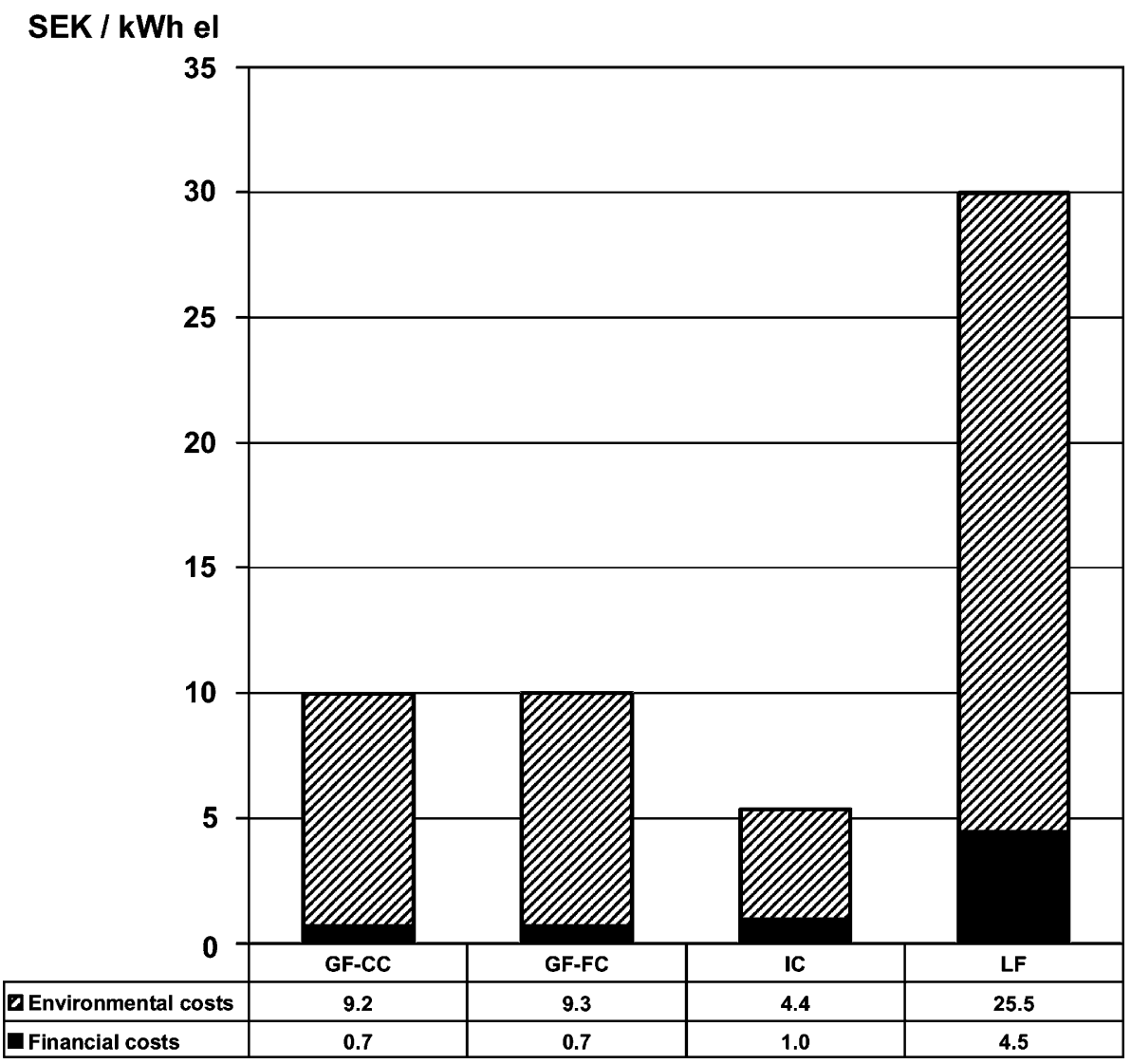

Fig. 6. Welfare costs when residue from gasification is treated as ash.

In the landfilling scenario, the largest contribution to the environmental costs comes from the emissions of VOC (volatile organic compounds) in the landfilling process and from the combustion of landfill methane in the gas engine. The environmental cost for the gasification scenarios comes mainly from landfilling of its residues, resulting in a leachate water enriched with copper. The environmental cost for incineration is mainly from the emissions of heavy metals, such as copper, mercury and chrome. The environmental costs are equal for the gasification scenarios. When considering environmental costs for the emissions for the core system only, flame combustion cost is twice higher than that of catalytic combustion, mainly due to the higher emissions of $\mathrm{NO}_{x}$ and, to a minor extent, VOC. This is not shown in the diagrams included.

In general, the total unit cost of production of electricity in the three thermal processes, and particularly in the gasification scenarios, is much higher than the current Swedish market value. This is, as mentioned above, mainly because of the copper leachate from the residues of gasification since copper and other heavy metals are heavily valued in the monetary valuation system used. It is worth mentioning that the gasification residues are assumed to behave in the same manner as ashes from incineration in landfilling. As for the incineration scenario, the influence from the copper leachate is not significant. The fact that the total cost in Fig. 6 is related to the 
electricity produced rather than the total energy including district heating makes the welfare cost for incineration higher than expected.

\section{Overall assessment}

With the aim of providing an overview picture of all the relative ecological and economic performances of the scenarios on the same scale, a radar diagram was used (Fig. 7). The results for the thermal technology chains have been normalised with the results for landfilling. The diagram shows the relative performance of the alternative technology chains without using any form of weighting.

A comparison of the catalytic combustion and flame combustion shows that all impact categories except acidification, eutrophication and photochemical oxidants remain the same. The gasification process is identical in the two alternatives. It is the combustion technology in the gas turbine that is different. This explains why the fuel consumption and the costs are not changed (a minor extra investment is made for the catalyst, but it is not noticeable in comparison to the total impact). Emissions of greenhouse gases are also identical. For the other impact categories, there are differences for most of the emissions involved in the impact assessment, but $\mathrm{NO}_{x}$ was the dominating one.

As shown in the radar diagram, gasification with catalytic combustion is competitive with incineration. The small difference for eutrophication is strongly dependent on the reduction of $\mathrm{NO}_{x}$ in the incineration plant. The explanation for this result is that a combined cycle in combination with natural gas as the compensatory power generation is a better systems solution than incineration with biomass as a compensatory fuel. When comparing flame combustion with incineration, the impacts in terms of acidification, eutrophication and photochemical oxidants are higher for flame combustion than for incineration. Financial costs are a little higher than for incineration. The data for costs was mainly based on assumptions, not actual costs, since there is

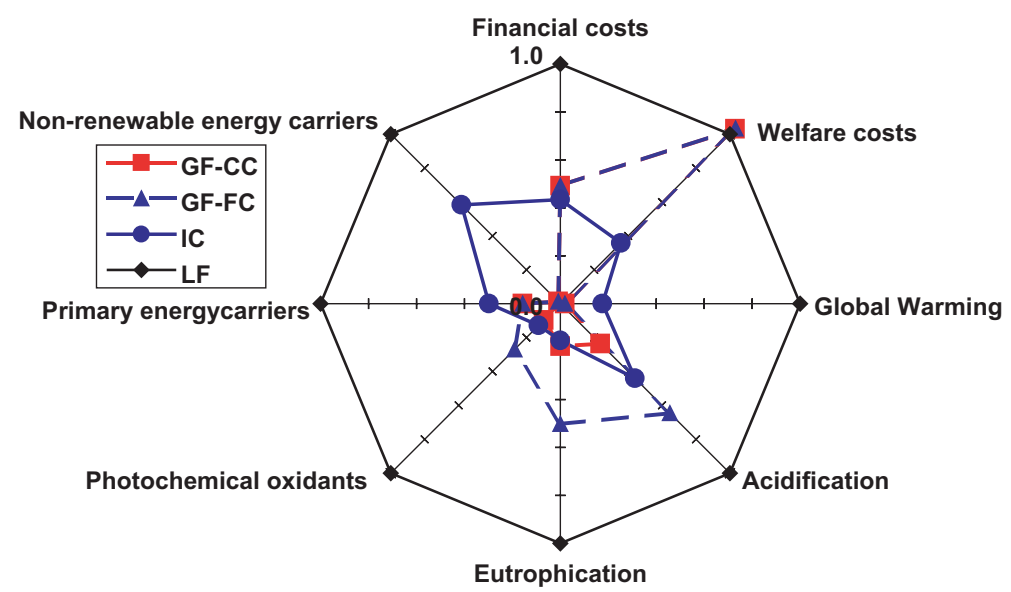

Fig. 7. Overall assessment of the scenarios relative to landfilling. 
no plant with gasification and catalytic combustion in operation. Hence, the difference in financial costs should be checked with improved knowledge.

With respect to all impact categories, landfilling should be avoided in comparison to thermal treatment. The best environmental solution seems to be gasification with catalytic combustion. It is better in all impact categories except for financial costs. This shows that environmental performance is not free of charge, and the price is illustrated here in financial terms.

\section{Uncertainty analysis and sensitivity analysis}

Uncertainty analysis and sensitivity analysis are useful in looking at the effects of assumptions and uncertainties on the results and conclusions of a study. While uncertainty analysis as applied to LCA is a technique in its infancy, it helps to characterise uncertainty in the results using ranges and/or probability distributions to determine uncertainty in the results and conclusions [30]. The use of probability theory requires data from a well documented LCI (life cycle inventory) database [31] and choosing an appropriate distribution function. Because of the lack of such database, the application of this method in this study is difficult.

Earlier attempts to address uncertainty in ORWARE studies were the identification of important parameters at different levels and then fixing the minimum and maximum values in consultation with relevant experts whenever possible or using a $\pm 10 \%$ where it was not possible to consult with an expert [32].

In this study, three types of analysis are used: (A) effects of input data uncertainty on impact categories, (B) effect of the leaching property of gasification's bottom product and (C) effects of changes in electricity and district heating prices on the overall assessment. The first two involve simulations, while the third requires no simulation. The uncertainty in economic input data are not considered at this stage.

\section{(A) Effects of input data uncertainty on impact categories}

A critical review of the input data was used as a way of reducing uncertainty through a parametric analysis using minimum and maximum values of selected input data by simulation. The procedure of the analysis that involves simulation consists of the following six steps:

1. For each impact category, identify the dominantly contributing system. This discriminates between the core system and external system (compensatory system for electricity and district heating production outside the core system). In this case, the dominant system is defined as the one that contributes more than $60 \%$ of the total impact in each technology chain or scenario.

Except for global warming in the incineration scenario where the external system dominates, the core system contributes from $66 \%$ to $93 \%$ of the impact in all the technologies chains.

2. For the dominant system, identify the substances that make significant contribution (set at equal to or more than $33 \%$ of the impact in question). 
Four substances, namely $\mathrm{CO}_{2}, \mathrm{CH}_{4}, \mathrm{NO}_{x}$ and $\mathrm{SO}_{x}$, are identified as important emissions in the core system, contributing from $35 \%$ to $100 \%$ of their respective impacts. For the incineration scenario, $\mathrm{CO}_{2}$ is identified as the only contributing emission in the external system.

3. Identify the parameters behind the formation of the important emissions. This requires a close look at the emissions and the model and other relevant technical parameters such as efficiency.

The composition of the feedstock in terms of the different fractions of biological carbon; carbon conversion in the gasifier, catalytic and flame combustors; degradation of carbon compounds in the landfill; $\mathrm{NO}_{x}$ formation in catalytic combustor, flame combustor, incinerator and gas engine; and $\mathrm{SO}_{x}$ formation in the incinerator are distinguished as important parameters for analysis in the core system. In the external system, the formation of $\mathrm{CO}_{2}$ during pre-combustion and production of the external electricity from natural gas and the efficiency of the natural gas power plant are recognised as important aspects.

4. Set the minimum and maximum values for the parameters identified in step 3 . There is a need to prioritise the most important ones.

In setting the minimum and maximum values, expert consultations, literature survey and thermodynamic calculations and reference to enforced regulatory provisions are applied.

5. Simulate.

A number of simulations are done based on three ranges of values (default value, minimum value and maximum value) for the selected number of parameters (see Table 4).

6. Discuss the changes in results and their implications.

A comparative analysis of the differences in the results from the simulations, including the uncertainty in input data, is done. Out of all the information processed from the simulations that resulted in a large amount of output data, the focus was only on a selected number of aspects.

From this result analysis, it can be seen that the rank of the scenarios does not change for global warming, whereas for acidification and eutrophication, the uncertainty involved affects the ranks of the scenarios. This is related to the uncertainty associated with the extent of reduction attained in $\mathrm{NO}_{x}$ formation in catalytic combustion relative to incineration.

The "default values" of the incineration scenario are based on enforced regulatory provisions, while its minimum values are based on the actual values from an incineration plant. In contrast with catalytic combustion, incineration achieves this reduction using gas cleaning as an end-ofpipe treatment, while catalytic combustion reduces the formation of $\mathrm{NO}_{x}$ in the first place.

Figs. $8-10$ show the uncertainty bands in impact categories for the three scenarios. The $Y$-axis displays the uncertainty bands including the default values corresponding to the values and units in Figs. 2-4. 
Table 4

Maximum and minimum values of important parameters ("first value" corresponds to default value)

\begin{tabular}{|c|c|c|c|}
\hline Parameter & Default value & Min & Max \\
\hline \multicolumn{4}{|l|}{ Composition } \\
\hline 1 C-sugar & 0.0927 & 0 & 0.0927 \\
\hline C-fat & 0.129 & 0 & 0.129 \\
\hline C-protein & 0.063 & 0 & 0.063 \\
\hline C-lignin & 0.0277 & 0.0277 & 0.1470 \\
\hline C-cellulose & 0.102 & 0.102 & 0.340 \\
\hline \multicolumn{4}{|l|}{$N O_{x}$ formation $(\mathrm{kg}$ ) } \\
\hline $6 \quad \mathrm{CC}^{\mathrm{a}} \mathrm{NO}_{x}$ per $\mathrm{MJ}(\mathrm{HHV})$ of pellets & $1.31 \times 10^{-5}$ & $1.31 \times 10^{-5}$ & $3.35 \times 10^{-5}$ \\
\hline $\mathrm{FC}^{\mathrm{a}} \mathrm{NO}_{x}$ per $\mathrm{MJ}(\mathrm{HHV})$ of pellets & $4.87 \times 10^{-5}$ & $3.35 \times 10^{-5}$ & $6.38 \times 10^{-5}$ \\
\hline $\mathrm{IC}^{\mathrm{a}} \mathrm{NO}_{x}$ per $\mathrm{MJ}(\mathrm{LHV})$ of waste & $1.37 \times 10^{-5}$ & $1.12 \times 10^{-5}$ & $1.37 \times 10^{-5}$ \\
\hline $\mathrm{GM}^{\mathrm{a}} \mathrm{NO}_{x}$ per $\mathrm{MJ}(\mathrm{LHV})$ landfill gas & $20 \times 10^{-5}$ & $5 \times 10^{-5}$ & $20 \times 10^{-5}$ \\
\hline \multicolumn{4}{|l|}{ Fossil $\mathrm{CO}_{2}\left(\mathrm{CO}_{2}-f\right)$ formation $(\mathrm{kg})$} \\
\hline $10 \mathrm{GF}^{\mathrm{a}} \mathrm{CO}_{2}$-f per Kg Ctot-f in pellets- & 1.142 & 1.142 & 1.49 \\
\hline $11 \mathrm{CC} \mathrm{CO}_{2}$-f per Kg Ctot-f in fuel gas & 2.194 & 2.194 & 3.68 \\
\hline $12 \mathrm{FC} \mathrm{CO}_{2}$-f per Kg Ctot-f in fuel gas & 2.194 & 2.194 & 3.68 \\
\hline \multicolumn{4}{|l|}{$S O_{x}$ formation $(\mathrm{kg})$} \\
\hline $13 \mathrm{IC} \mathrm{SO}_{x}$ per MJ(LHV) of waste & $6.006 \times 10^{-5}$ & $6.006 \times 10^{-5}$ & $8.42 \times 10^{-5}$ \\
\hline
\end{tabular}

${ }^{a}$ CC: catalytic combustor, FC: flame combustor, IC: incinerator, GF: gasifier, GM: gas motor.

The landfilling scenario is excluded from the diagram in order to render the diagram discernible. There is no information lost in doing so since, for the uncertainty ranges examined, the landfill scenario is incomparably worse for the impact categories considered.

Most of the default values coincided with the minimum values, reflecting the optimistic feature of the data used. Usually, uncertainty analysis discriminates between the default, minimum and maximum values.

\section{(B) Effect of the leaching property of gasification's bottom product on the external cost}

This aspect looks at whether the bottom product from gasification has the same leaching property as ash or as slag from the incineration plant. To this end, a sensitivity analysis that deals with management of the gasification residues is done. Since the waste gasification technology is not well established, its residual products are new to ORWARE analysis, and it was not easy to decide whether to treat them as slag or ash. Such a choice matters since it has also to do with the question of how the landfilling model works when provided with such products. The existing landfilling models were developed based on data from ash and slag from incineration. Probably, a completely new model has to be developed in the future. In dealing with this problem for the time being, a sensitivity analysis was done by considering the gasification residue to (1) behave in the same way as ash from incineration or (2) as slag from incineration.

The differences between these two cases were evaluated in terms of environmental costs or the external cost part of LCC related to emissions to air, water and soil. The environmental costs in 


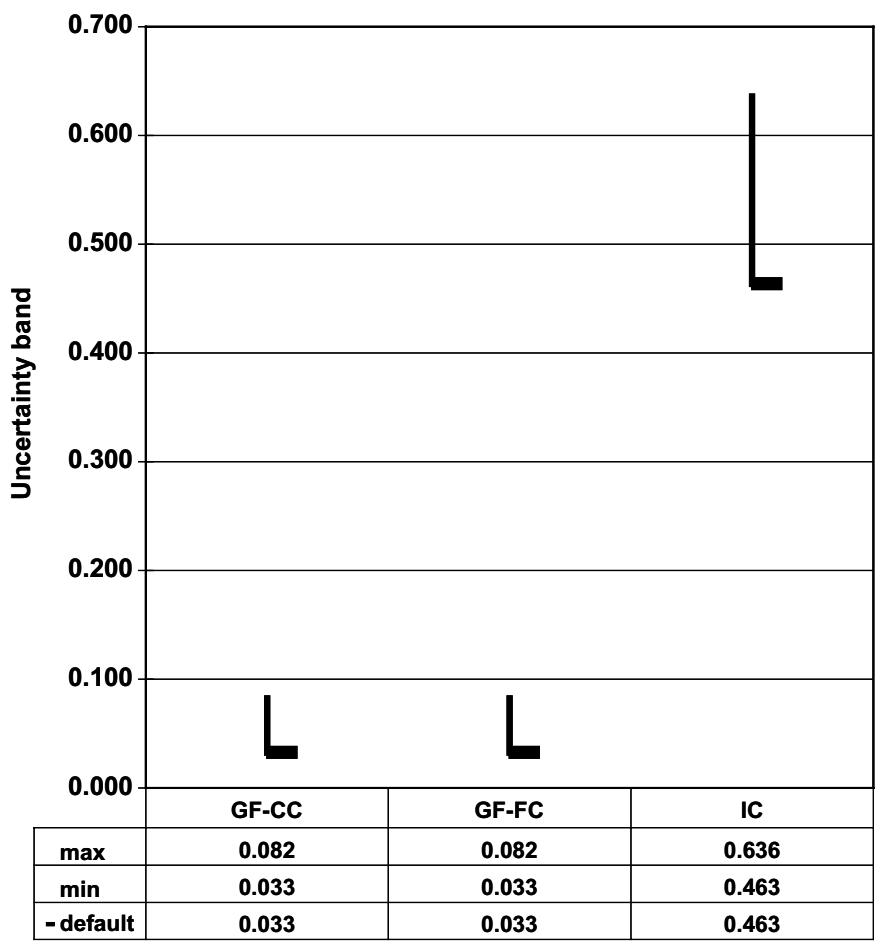

Fig. 8. Uncertainty band for global warming.

Fig. 6 correspond to the case where the residue is taken to the landfill as ash. The rank of the scenarios becomes different when it is treated as slag, as shown in Fig. 11.

This change in the rank of scenarios is because of the heavy metals (mainly copper) contained in the residues. Heavy metals including copper behave differently when landfilled as ash or as slag according to the current landfilling model. Much more copper is leached out as water effluent when the residue is landfilled as ash than when landfilled as slag. The cheapest alternative in this case becomes the scenarios with gasification.

\section{(C) Effects of changes in electricity and district heating prices on overall assessment}

Without a need for simulation, the revenues from sold heat and power were altered for each scenario (Figs. 12 and 13). Higher energy prices are likely to be introduced in the future due to more strict environmental requirements. It was, thus, of interest to investigate the sensitivity of the results to this change. The price sensitivity analysis was based on financial costs but could also be developed to include environmental costs, although it is not clear at the moment how to do this in a proper way.

Fig. 12 illustrates the relation between treatment cost per ton of waste and the revenue from district heating. The revenue from the electricity delivered is not considered. From the landfill scenario, no heat was recovered which means that no cost reduction could be achieved. Incin- 


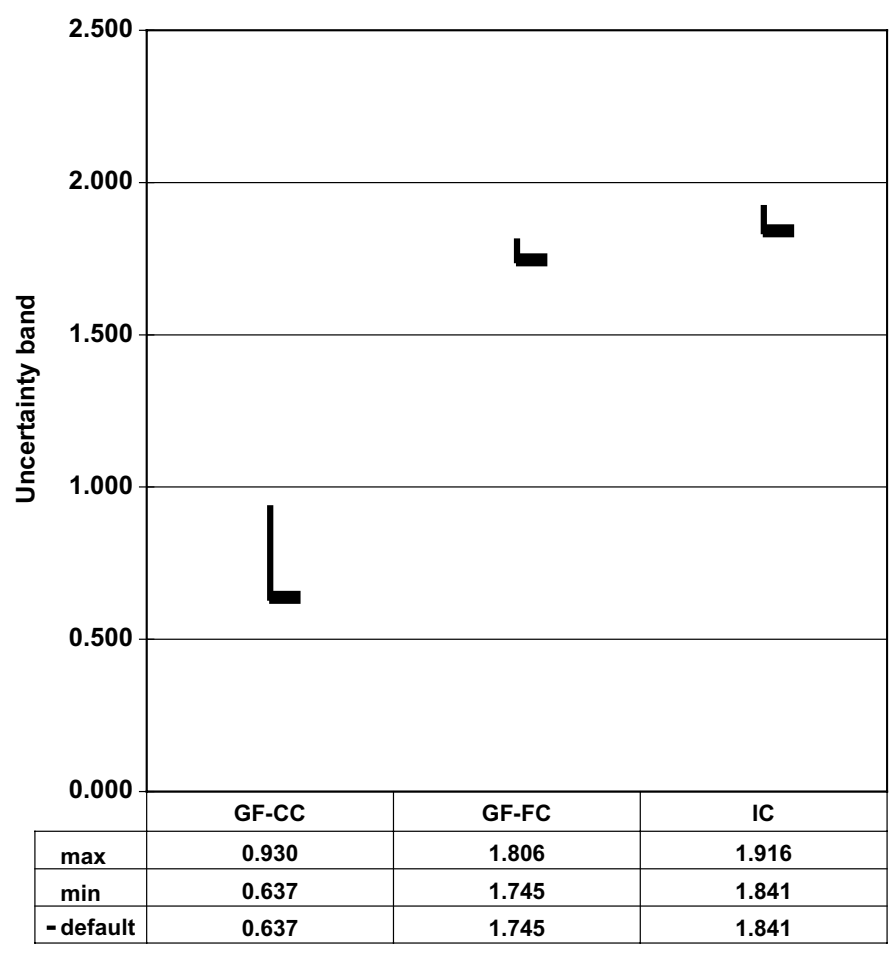

Fig. 9. Uncertainty band for acidification.

eration is profitable at a price just below $0.15 \mathrm{SEK}{ }^{1} / \mathrm{kW} \mathrm{h}$. The treatment costs for the gasification scenarios become lower in the same way as for the incineration scenario, but since the investments costs are higher for gasification followed by combustion (flame or catalytic), the total cost is always higher than for incineration. The picture in Fig. 12 is in agreement with reality, since neither landfilling nor gasification are processes designed for heat recovery.

When only electricity is priced, the picture changes completely (Fig. 13). All technologies respond to the changes in price, and the ones with the highest power production capacity, i.e. the scenarios with gasification, respond rather quickly.

Incineration is profitable at a price of approximately $0.6 \mathrm{SEK} / \mathrm{kW} \mathrm{h}$ and landfilling far beyond 1 $\mathrm{SEK} / \mathrm{kWh}$. At a price of about $0.2 \mathrm{SEK} / \mathrm{kWh}$, the scenarios with gasification become cheaper than landfilling, and at around 0.55 , they become profitable. For these scenarios to compete with incineration, the price of electricity has to be about $0.5 \mathrm{SEK} / \mathrm{kWh}$.

\section{Discussion and conclusions}

The discussion and conclusions focus first on the results of the assessment and then on the use of ORWARE as a TA tool.

\footnotetext{
${ }^{1}$ SEK: Swedish currency (1 SEK =0.13 US \$ based on exchange rates on March 11, 2004).
} 


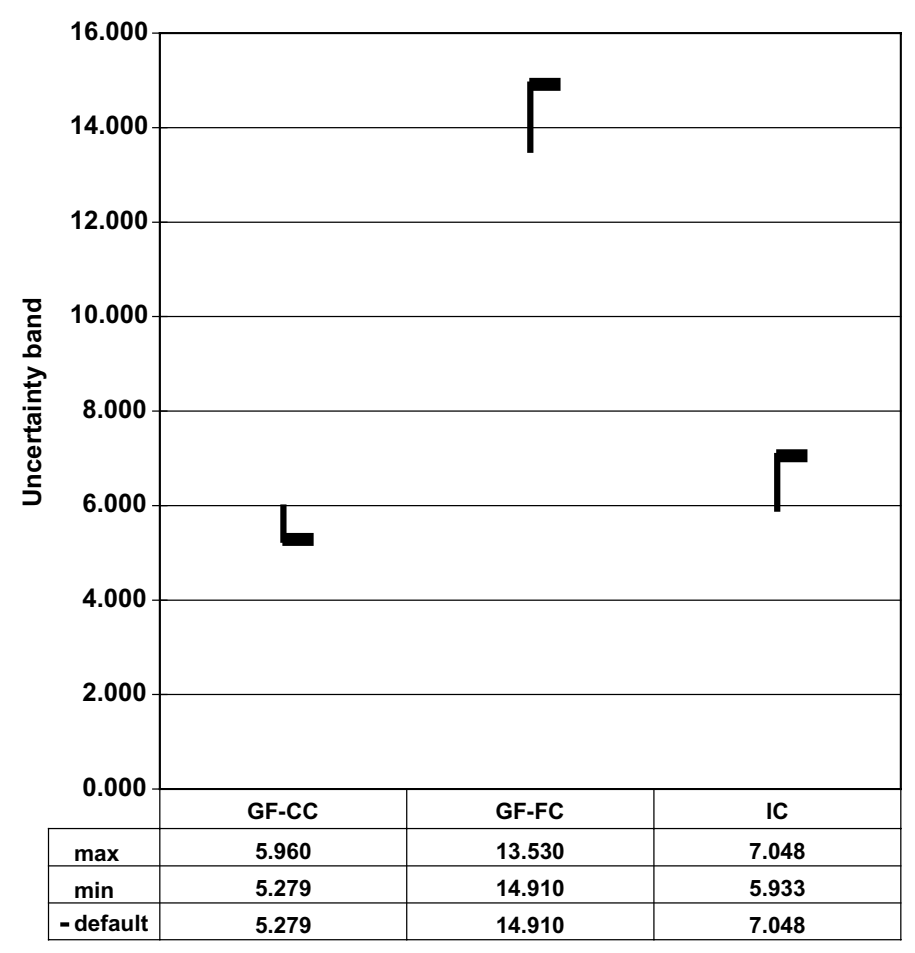

Fig. 10. Uncertainty band for eutrophication.

\subsection{On the results}

The primary goal of the thermal technologies studied here was energy recovery in terms of electricity. The simulations showed that a decreased use of landfilling in favour of an increased energy recovery from waste is positive for the impact categories considered. Gasification followed by catalytic combustion with energy recovery in a combined cycle appears to be the most competitive technology from an ecological point of view. It is more expensive than incineration but has better ecological performance. There is a possibility that it pays off in a relatively shorter time if the price of electricity rises. This conclusion depends, however, on the assumption that the technology chain connecting gasification and catalytic combustion would perform properly and that the input fuel is of high quality. The remarks regarding the results hold true if the "real" values are in close vicinity with the default values as shown in the uncertainty analysis.

An important improvement for the catalyst technology can be expected when it is fully developed. Considering the relatively low cost of catalysts, the advantages in terms of decreased emissions, primarily of $\mathrm{NO}_{x}$, are great. These advantages can be seen both from an ecological and an economic perspective. The economic aspect is important in terms of the Swedish tax system where plants using technologies with low emissions of $\mathrm{NO}_{x}$ are entitled to a financial reward. Some problems remain to be solved, e.g. handling the gasification residue. This implies that a technology can not be considered sustainable unless the total life cycle impact is fully addressed and thereby reduced. In this case, it is beneficial that gasification is better than incineration during 


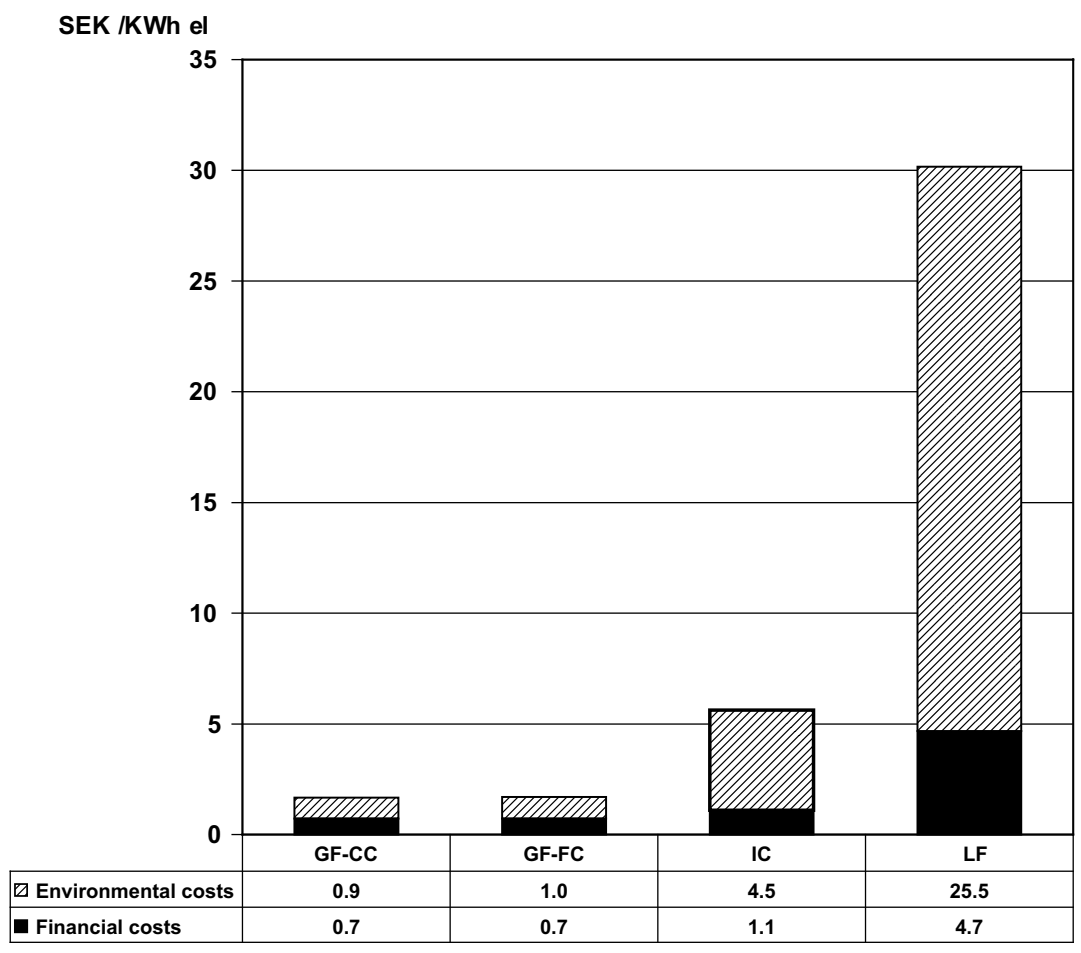

Fig. 11. Welfare costs when residue from gasification is treated as slag.

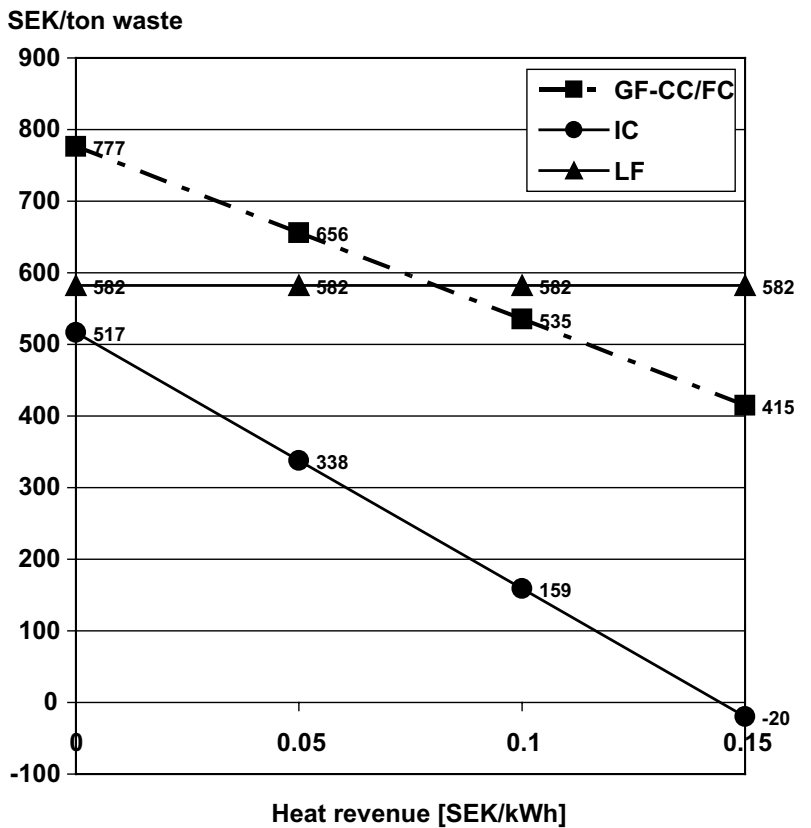

Fig. 12. Sensitivity of treatment cost to changes in price of district heating. 


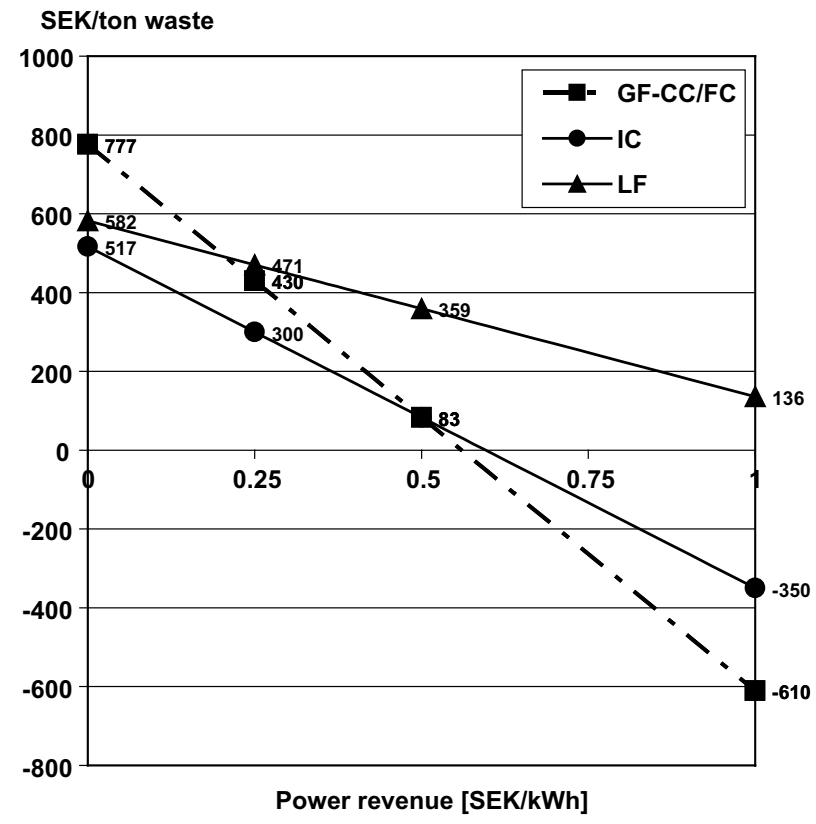

Fig. 13. Sensitivity of treatment cost to changes in price of electricity.

the operation phase with regard to gaseous pollutants such as $\mathrm{NO}_{x}$, but this would be of minor benefit if the gasification residues would cause severe environmental problems in the future.

A unique feature of this study was the possibility of comparison between specific technologies and broader systems. This feature makes ORWARE not only a tool of technology assessment but also a tool for assessment of system design alternatives. It was possible to make a comparison both between a combined cycle and a Rankine cycle (a system pair) and at the same time between flame combustion and catalytic combustion (a technology pair). To use gasification just as a treatment technology is not more appealing than incineration, but the possibility of combining gasification with a combined cycle is indeed attractive in terms of electricity production. For the data used in this assessment, the overall efficiency is lower than for incineration, but the power production is relatively higher. Since the marginal production of electricity is more polluting than the alternative to waste incineration, namely combustion of biomass, gasification combined with catalytic combustion is a sound investment from an ecological point of view. The benefit of catalytic combustion compared to flame combustion, namely the low level of $\mathrm{NO}_{x}$ emissions, guides eutrophication, acidification and formation of photochemical oxidants. In a nutshell, a combination of a combined cycle and catalytic combustion of gasified waste is the most competitive technology chain.

\subsection{On the use of ORWARE as a TA tool}

This section starts with a TA typology from the literature that sets the context for the discussions and remarks made. 
In their analysis of generations of TA discourse and five institutional forms of TA, Berloznik and Van Langenhove [8] differentiated between academic, industrial, parliamentary, executive power and laboratory TA. Their interest was to lay a foundation for incorporating TA in R\&D processes.

When ORWARE was coined an environmental technology chain assessment (ETCA) tool for the first time in Assefa et al. [16], there was only one study used to illustrate the claim. No economic assessment was made and, thus, the term ETCA.

The current study is the third of its kind where ORWARE has been used in assessment of different technologies and not just systems analysis of waste management. The first two were by Assefa [33] and by Fahlstedt [34]. In most other recent ORWARE studies and these three, waste has been used as a fuel, but the analyses have, more and more, taken the character of an analysis of an energy system rather than a waste management system [15]. This is an interesting development as one of the future ORWARE applications that have been anticipated within the research group.

In the first study, there was a focus on fuel production for transport work and the links between waste management, energy recovery and the transport system. The second study introduced a new functional unit, namely district cooling produced from incineration, besides electricity and district heating. The system design in Fahlstedt's study had a focus on high overall efficiency. The system design in Assefa's study, on the other hand, emphasised the substitution of the most polluting activities (waste substitutes petrol in cars rather than biofuel in district heating). This study by Assefa [33] was more aimed at an examination of an emerging technology. The data was more uncertain than in the previous ORWARE studies.

There are important problems with these types of assessments that deal with new technologies. One of the most serious problems is comparing existing full scale technologies with unestablished technologies that do not exist in full scale. With the help of expert discussions and using contemporary literature, some estimates on data can be made. However, the quality of such data is inferior to that for existing facilities that are using a technology that has been developed for decades. There is also a fundamental difference between the data uncertainty for emissions used in the calculations of ecological impact and the financial data used for economic cost calculations. In the first case, emissions have at least been measured, though associated with a variety of uncertainties, although there is a need to look closer at each and every parameter with respect to the uncertainty of different data points. The financial costs for Scenarios 1 and 2 were only estimated based on pilot studies. Uncertainty analysis on these costs should be done in the future.

This TA study is different from the previous ones due to its close association with an ongoing R\&D work at the laboratory and pilot scale. There is a need to develop tools like ORWARE that can be used for R\&D TA [8] that provide insight to R\&D researchers concerning a broader perspective of the impact of their research and development work. Furthermore, such tools, together with other approaches, have the potential of highlighting an idea on where the next invention or R\&D work should focus.

\section{Acknowledgements}

The authors are grateful for the collaboration by Professor Sven Järås and Henrik Kusar at the Division of Chemical Technology, Royal Institute of Technology (KTH), Sweden, during the 
course of the research project entitled Systems Analysis of Waste Combustion. We extend our thanks also to The Swedish Energy Agency (STEM) for funding the research.

\section{References}

[1] Wood FB. Lessons in technology assessment: methodology and management at OTA. Technol Forecast Soc Change 1997;54:145-62.

[2] Brooks H. Technology assessment. In: Salomon J-J, Sagasti FR, Sachs-Jeantet C, editors. The uncertain quest: Science, technology, and development. Tokyo, Japan: United Nations University Press; 1994.

[3] Ludwig B. The concept of technology assessment - an entire process to sustainable development. Sustain Develop 1997;5:111-7.

[4] van Eijndhoven JCM. Technology assessment: product or process. Technol Forecast Soc Change 1997;54:269-86.

[5] Porte TML. New opportunities for technology assessment in the post-OTA world. Technol Forecast Soc Change 1997;54:199-214.

[6] Bimber B, Guston DH. Introduction: the end of OTA and the future of technology assessment. Technol Forecast Soc Change 1997;54:125-30.

[7] Hill CT. The congressional office of technology assessment: a retrospective and prospects for the post-OTA world. Technol Forecast Soc Change 1997;54:191-8.

[8] Berloznik R, Langenhove LV. Integration of technology assessment in R\&D management practices. Technol Forecast Soc Change 1998;58:23-33.

[9] Pitt J. What engineers know. J Soc Philos Technol 2001;5:3.

[10] UNEP/IETC. Work-book for training in Environmental Technology Assessment for decision makers. Technical Publication Series [5]. UNEP International Environmental Technology Center, Osaka/Shiga, Japan, 1997.

[11] UNEP/IETC. Technical workbook on environmental management tools for decision analysis. Technical Publication Series [14]. UNEP International Environmental Technology Center, Osaka, Japan, 2000.

[12] Armstrong JE, Harman WW. Strategies for conducting technology assessments. Colorado: Westview press; 1980.

[13] Assefa G, Eriksson O, Järås S, Kusar H. Life Cycle Assessment of Thermal Technologies. An environmental and financial systems analysis of gasification and combustion of waste and biomass. Project Report, P 10547-1, Royal Institute of Technology, Stockholm, Sweden, 2002.

[14] Björklund A. Environmental systems analysis of waste management with emphasis on substance flows and environmental impact. Licentiate Thesis, TRITA-KET-IM 1998:16, Department of Chemical Engineering and Technology, Division of Industrial Ecology, Royal Institute of Technology, Stockholm, 1998.

[15] Eriksson O, Frostell, B. An approach to sustainability assessment of energy systems. In: Silveria S, editor. Building sustainable energy systems: Swedish Experiences. Swedish National Energy Administration, 2001.

[16] Assefa G, Björklund A, Eriksson O, Frostell B. ORWARE: an aid to environmental technology chain assessment. $\mathrm{J}$ Cleaner Product, in press.

[17] Eriksson O, Frostell B, Björklund A, Assefa G, Sundqvist J-O, Granath J, et al. ORWARE—a simulation tool for waste management. Resour Conservat Recycl 2002;36:287-307.

[18] Miser HJ, Quade ES. Handbook of systems analysis. Chichester, UK: John Wiley; 1995.

[19] Baccini P, Brunner PH. Metabolism of the anthroposphere. Berlin: Springer-Verlag; 1991.

[20] van der Voet E, Klein R, van Oers L, Heijungs R, Huele R, Mulder P. Substance flow analysis through the economy and the environment. Part I: System definition. Environ Sci Pollut Res 1995;2(2):89-96.

[21] ISO. Environmental Management—Life Cycle Assessment—Principles and Frame Work. ISO 14040:1997(E), 1997.

[22] Wrisberg N, Udo de Haes HA, Bilitewski B, Bringezu S, Bro-Rasmusse F, Clift R, et al. Demand and supply of environmental information. In: Wrisberg N, Udo de Haes HA, editors. Analytical tools for environmental Design and Management in a systems perspective The combined use of tools. Boston: Kluwer Academic Publishers; 2002.

[23] Järås S. Catalytic combustion of gasified waste - with systems analysis: ORWARE. Report to Swedish National Energy Administration, dnr 5110P-00-00181, 2001 [in Swedish]. 
[24] Bridgwater AV. The technical and economic feasibility of biomass gasification for power generation. Fuel 1995;74(5):631-53.

[25] Sydkraft Värnamo Demonstration Plant. Malmö, Sweden, 2001.

[26] Björklund A. Environmental systems analysis of waste management. Experiences from applications of the ORWARE model. Doctoral Thesis, TRITA-KET-IM 2000:15, Department of Chemical Engineering and Technology, Division of Industrial Ecology, Royal Institute of Technology, Stockholm, Sweden, 2000.

[27] Uppenberg S, Lindfors L-G. EPD Product specific starting points for vehicle fuels, PSR 1999:6. Available from: http://www.sms-standard.se/pdf/epd/psr9906.pdf, 1999 [in Swedish].

[28] Sundqvist J-O, Baky A, Carlsson Reich M, Eriksson O, Granath J. How should household waste be treated? Assessment of different treatment methods. IVL Report 1462, Swedish Environmental Research Institute, Stockholm, Sweden, 2002 [in Swedish].

[29] Johansson J. A monetary valuation weighting method for life cycle assessment based on environmental taxes and fees. Master Thesis in Natural Resources Management, Department of Systems Ecology, Stockholm University, Sweden, 1999.

[30] ISO Environmental labels and declarations-Type III environmental declarations. ISO 14025: 2000, 2000.

[31] NREL. The US LCI database project. Working Paper No. 6: Data Quality, Variability and Uncertainty in LCI. Available from: <http://www.nrel.gov/lci/pdfs/no6_dataquality_etc.pdf>, accessed on 10 February, 2004.

[32] Eriksson O, Baky A. Identification and testing of potential key parameters in systems analysis of municipal solid waste management. Manuscript, 2003.

[33] Assefa G. Environmental systems analysis of waste management. Prospects of hydrogen production from waste for use in fuel cell vehicles. Masters Thesis, TRITA-KET-IM 2000:3, Department of Chemical Engineering and Technology, Division of Industrial Ecology, Royal Institute of Technology, Stockholm, Sweden, 2000.

[34] Fahlstedt C. Cogeneration of electricity, district heating and district cooling through thermal processing of wastea systematic technology assessment of energy-turnover, environmental and economic performance. Masters Thesis, TRITA-KET-IM 2002:19, Department of Chemical Engineering and Technology, Division of Industrial Ecology, Royal Institute of Technology, Stockholm, Sweden, 2002 [in Swedish]. 